\title{
A large scale classification of molecular fingerprints for the chemical space representation and SAR analysis
}

\author{
Fabian López-Vallejo*, Jacob Waddell, Austin B Yongye, Richard A Houghten, José L Medina-Franco \\ From 7th German Conference on Chemoinformatics: 25 ClC-Workshop \\ Goslar, Germany. 6-8 November 2011
}

Fingerprint-based structure representation has a broad range of applications including, but not limited to, diversity analysis, compound classification, chemical space visualization [1], activity landscape modelling and similarity searching. It has been shown that depending on the particular fingerprints used, the outcome of similarity searching [2] or activity landscapes [3] can be very different. Combining structure representations is a common practice to increase the performance of similarity searching [4]. Also, combining representations for activity landscape modelling has been proposed to generate robust descriptive SAR models [5]. However, the selection of fingerprints to be combined is not an easy task. As part of our efforts to select fingerprint representations to generate consensus representations of chemical space and activity landscapes $[5,6]$ herein we discuss the results of a systematic comparison of more than $102 \mathrm{D}$ and 3D fingerprint representations in terms of performance in diversity analysis (as opposed to similarity searching). We employed more than 20 data sets from different sources relevant to drug discovery. In this work the widely used Tanimoto coefficient was employed. The approach presented here can be easily extended to other similarity measures, additional fingerprints and molecular databases. We also discuss the typical mean/median similarity values of selected fingerprints across databases from different sources.

\section{Published: 1 May 2012}

\section{References}

1. Medina-Franco JL, Martínez-Mayorga K, Giulianotti MA, Houghten RA, Pinilla C: Visualization of the Chemical Space in Drug Discovery. Curr Comput-Aided Drug Des 2008, 4:322-333.

Torrey Pines Institute for Molecular Studies, Port St. Lucie, Florida, 34987, USA
2. Bender A: How Similar Are Those Molecules after All? Use Two Descriptors and You Will Have Three Different Answers. Expert Opin Drug Discovery 2010, 5:1141-1151.

3. Wassermann AM, Wawer M, Bajorath J: Activity Landscape Representations for Structure-Activity Relationship Analysis. J Med Chem 2010, 53:8209-8223.

4. Chen B, Mueller C, Willett P: Combination Rules for Group Fusion in Similarity-Based Virtual Screening. Mol Inf 2010, 29:533-541.

5. Yongye A, Byler K, Santos R, Martínez-Mayorga K, Maggiora GM, MedinaFranco JL: Consensus Models of Activity Landscapes with Multiple Chemical, Conformer and Property Representations. J Chem Inf Model 2011, 51:1259-1270.

6. López-Vallejo F, Nefzi A, Bender A, Owen JR, Nabney IT, Houghten RA, Medina-Franco JL: Increased Diversity of Libraries from Libraries: Chemoinformatic Analysis of Bis-Diazacyclic Libraries. Chem Biol Drug Des 2011, 77:328-342.

\section{doi:10.1186/1758-2946-4-S1-P26}

Cite this article as: López-Vallejo et al:: A large scale classification of molecular fingerprints for the chemical space representation and SAR analysis. Journal of Cheminformatics 2012 4(Suppl 1):P26.

\section{Publish with ChemistryCentral and every scientist can read your work free of charge \\ "Open access provides opportunities to our colleagues in other parts of the globe, by allowing anyone to view the content free of charge." \\ W. Jeffery Hurst, The Hershey Company. \\ - available free of charge to the entire scientific community \\ - peer reviewed and published immediately upon acceptance \\ - cited in PubMed and archived on PubMed Central \\ - yours - you keep the copyright \\ Submit your manuscript here: \\ http://www.chemistrycentral.com/manuscript/ \\ Chemistry Central}

